\title{
Eléctrico, auténtico y precario: el sonido y los nuevos públicos en los espectáculos de rock de los ochenta montevideanos
}

Leandro Delgado

Universidad Católica del Uruguay. ledelgad@ucu.edu.uy ORCID: https://orcid.org/0000-0001-9485-766X

Federico Farachio

Universidad Tecnológica del Uruguay. federico.farachio@utec.edu.uy ORCID: https://orcid.org/0000-0001-9321-7142

Fecha de finalización: 30 de agosto de 2021. Recibido: 31 de agosto de 2021. Aceptado: 11 de noviembre de 2021. DOI: https://doi.org/10.26422/aucom.2021.1002.del

\section{Resumen}

La crítica a los problemas sonoros en los espectáculos de rock en vivo es una constante en la prensa cultural y musical de los ochenta montevideanos. Estos problemas fueron consecuencia de tres motivos principales: la dificultad económica de los músicos para acceder a la instrumentación eléctrica, los sistemas de amplificación deficientes y la inadecuación acústica de los locales dedicados a este tipo de espectáculos. El presente artículo investiga estas críticas y reflexiona sobre los vínculos que periodistas y músicos establecieron entre los problemas de amplificación y una supuesta crisis del género, así como sus dificultades para caracterizar las nuevas audiencias juveniles en la nueva democracia. La crisis del rock estuvo ligada a la imposibilidad de poder incorporarlo a una tradición musical nacional ante la dificultad de hacerse oír en los términos exigidos por el género. Los obstáculos para caracterizar a las nuevas audiencias son consecuencia de una noción de público masivo, homogéneo y característico de los grandes recitales de canto popular en tiempos de dictadura. A partir de una exhaustiva encuesta de prensa realizada entre 1984 y 1987, se analizan los testimonios de periodistas y músicos desde la perspectiva de los estudios culturales y los estudios sonoros, así como, en mayor detalle, los testimonios de los integrantes de la banda Los Tontos respecto a sus estrategias para superar las dificultades económicas y a sus percepciones actualizadas de los nuevos públicos.

Palabras clave: ochentas, rock uruguayo, sonido, sound studies.

\section{Electric, authentic, and precarious: sound quality and new rock music audiences in Uruguay during the 1980s}

\section{Abstract}

During the 1980s, in Montevideo, Uruguay, music and cultural critics constantly lambasted the sound quality at live rock shows. This recurring issue was due to three main factors: the econo- 
Leandro Delgado, Federico Farachio

Eléctrico, auténtico y precario: el sonido y los nuevos públicos en los espectáculos de rock de los ochenta montevideanos

mic challenge of acquiring electronic equipment, the deficiency of sound amplification systems, and the acoustic inadequacy of most venues dedicated to rock shows. In the following paper, we analyze the above criticisms and reflect on the relationship between journalists and musicians, as they debated sound amplification and the alleged crisis of rock music. We also look at the difficulties they faced in characterizing the new youth audiences that had emerged after the democratic transition. The crisis of rock music was sparked by the impossibility of incorporating rock into - and having it be heard within the constraints of - the broader tradition of Uruguayan music. Moreover, characterizing youth audiences proved complicated because of pre-existing notions of audiences as massive and homogenous, typical of the large-scale canto popular concerts during the dictatorship. Following a thorough survey of press coverage between 1984 and 1987, we analyze the statements of journalists and musicians, doing so from the point of view of cultural and acoustic studies. More specifically, we look at the statements made by members of the band Los Tontos, who described their strategies for overcoming economic hurdles and their perception of the period's new music audiences.

Keywords: Eighties, Uruguayan rock music, sound, acoustic studies, music studies.

\section{Elétrico, autêntico e precário: o som e os novos públicos nos shows de rock dos anos oitenta de Montevidéu}

\section{Resumo}

A crítica aos problemas de som nos shows de rock ao vivo é uma constante na imprensa cultural e musical de Montevidéu dos anos oitenta. Estes problemas foram consequência de três razões principais: a dificuldade financeira dos músicos em aceder à instrumentação eléctrica, os sistemas de amplificação deficientes e a inadequação acústica das instalações dedicadas a este tipo de espectáculos. Este artigo investiga essas críticas e reflete sobre as ligações que jornalistas e músicos estabeleceram entre problemas de amplificação e uma suposta crise de gênero, bem como suas dificuldades em caracterizar os novos públicos juvenis na nova democracia. A crise do gênero estava ligada à impossibilidade de incorporar o rock à tradição musical nacional pela dificuldade de se fazer ouvir nos termos exigidos pelo gênero. A dificuldade de caracterização dos novos públicos decorre de uma noção de público massivo e homogêneo característico dos grandes recitais de canção popular em tempos de ditadura. A partir de uma exaustiva pesquisa de imprensa realizada entre 1984 e 1987, os depoimentos de jornalistas e músicos são analisados na perspectiva dos estudos culturais e dos estudos do som. Os depoimentos dos integrantes da banda Los Tontos são analisados com mais detalhes, dadas suas estratégias originais para superar as dificuldades econômicas, bem como suas percepções atualizadas de novos públicos.

Palavras-chave: anos oitenta, rock uruguaio, som, sound studies.

\section{Introducción}

El rock como género musical y la cultura juvenil asociada surgieron con particular intensidad entre fines de la dictadura uruguaya (1985) y fin de la década. Tanto los músicos de rock como los jóvenes roqueros de los sesenta y setenta habían atravesado un largo impasse ante la acción represiva del gobierno cívico militar, que tuvo un particular encono contra los jóvenes que adoptaron la estética roquera en su presencia pública (Peláez, 2002). Mientras la mayoría de los músicos abandonaba el país, los jóvenes vin- 


\section{Austral Comunicación \\ Volumen 10, número 2 (Diciembre de 2021): 461-483 ISSN (I) 2313-9129. ISSN (E) 2313-9137}

culados con el rock se replegaron al interior de sus hogares y los recitales prácticamente desaparecieron (Peláez, 2002). Mientras tanto, el canto popular surgió como una manifestación musical y cultural masiva de resistencia cultural y política de izquierda que abrevaba de la música folklórica sin ninguna referencia al rock. ${ }^{1}$ Reprimido por la dictadura y desestimado por el canto popular, el rock prácticamente desapareció de la arena cultural montevideana.

La reaparición progresiva del rock en Uruguay coincidió con el proceso de transición a la democracia. ${ }^{2}$ Específicamente, se puede establecer 1983 como el año del resurgimiento "oficial" del rock en Uruguay, el cual adoptaba al punk rock como género musical de acuerdo con las transformaciones que venía atravesando en el mundo desarrollado desde los setenta. ${ }^{3}$ El hito que marcó esta fecha fue la aparición televisiva de la banda Los Estómagos en el cierre del programa humorístico Telecataplúm, que continuaba la tradición humorística que había inaugurado en los sesenta y que, en los ochenta, renovaba su convocatoria, también por su posición crítica frente a la dictadura. ${ }^{4}$ La banda se iba a convertir en la más conocida y representativa del rock de la nueva democracia.

Las expresiones del punk rock del mundo desarrollado eran conocidas por algunos productores del momento desde algunos años antes (Delgado, 2016). Existieron programas de radio y de televisión que contemplaban las manifestaciones del rock nacional en el contexto del rock de Europa y Estados Unidos (Meridiano Juvenil en la radio de los setenta y ochenta ${ }^{5}$ y Alternativa en la televisión de los ochenta). Sin embargo, no hubo casi referencias al surgimiento del rock en las páginas de la prensa sino hasta 1984, casi a un año de la presentación de Los Estómagos, cuando el periodista Carlos Da Silveira (1984) menciona la participación de la banda Los Tontos en un festival de música popular, mención que quizá sea la primera sobre músicos de rock en la prensa. Estas referencias al resurgimiento del rock estaban inscriptas en el contexto de los cam-

\footnotetext{
El canto popular fue un fenómeno musical masivo y juvenil que surgió en los setenta como resistencia a la dictadura. Un panorama de los autores y tendencias musicales de este movimiento pueden consultarse en Rodríguez Barilari y Da Rosa (1980).

2 Una periodización ajustada, así como los hitos que marcaron la transición a la democracia, se pueden encontrar en Caetano y Rilla (1987).

3 Testimonios de periodistas argentinos en Montevideo señalan la marcada impronta punk del rock montevideano, a diferencia del rock argentino (Rodríguez, 2012).

4 Una descripción detallada de la participación de Los Estómagos en Telecataplúm se puede encontrar en Delgado (2016).

5 Este programa fue casi el único que siguió difundiendo el rock progresivo inglés y estadounidense de los setenta y, por lo tanto, fue un refugio para aquellos roqueros de la "vieja guardia" que no encontraban reductos donde asistir a recitales. Para más detalles sobre este programa, se puede consultar José "Deqo" Núnez... (2015). Es importante destacar también que, durante el período analizado, existieron bandas vinculadas al rock progresivo y al jazz rock que no recibieron la misma atención que aquellas vinculadas al punk rock, tales como Polenta, Desolángeles, Siddharta y Zafhfaroni, entre otras. Sus presentaciones tienen muy escasa presencia en la prensa del momento.
} 
Leandro Delgado, Federico Farachio

Eléctrico, auténtico y precario: el sonido y los nuevos públicos en los espectáculos de rock de los ochenta montevideanos

bios que atravesaba la música popular en la nueva democracia, conmovida también por el paulatino regreso del exilio de músicos principales. ${ }^{6}$

Es importante recordar, para este trabajo, el discurso particular que la generación vinculada al rock de los ochenta fue creando para sí misma. En este período, un grupo de periodistas e intelectuales reflexionó, interpretó y difundió, a través de diferentes publicaciones periodísticas y académicas, la noción de una "orfandad" o rechazo hacia las generaciones anteriores, estableciendo el lugar y el sentido que el rock ocupaba en la tradicional cultural. Tal "orfandad" iba acompañada de un pesimismo respecto a sus proyecciones en el futuro del país, expresado en varios productos culturales, como por ejemplo la acuñación de la expresión generación ausente y solitaria por el fanzine GAS Subterráneo, uno de los más representativos del período, o los testimonios de los jóvenes entrevistados en el documental Mamá era punk de Guillermo Casanova (1988). ${ }^{8}$

A pesar de que existieron espacios dedicados exclusivamente al rock, las polémicas establecidas en la prensa entre diferentes periodistas dan cuenta de una preocupación por insertar al género en la continuidad de una tradición cultural. En este sentido, el rock como género y cultura ${ }^{9}$ se presentó como expresión visible de otros aspectos de la cultura de la posdictadura que no convocaban, por sí mismos, a una discusión en sus propios términos. En otras palabras, la discusión sobre el rock como cultura y su lugar en una tradición generó una única y duradera polémica sobre toda la cultura de su tiempo, alimentada periódicamente por defensores y exégetas a partir de la crítica de discos y recitales en vivo, así como de numerosas entrevistas a las nuevas generaciones de músicos. ${ }^{10}$

Esta conversación en la prensa se extendió por más de tres años, desde enero de 1986 hasta fines de 1988. Son numerosos los aspectos de la cultura que se discutieron uno tras otro sin límite de continuidad: imperialismo cultural, políticas culturales, culturas juveniles, identidad nacional, desarrollo tecnológico, nuevos públicos, etcétera. Para los objetivos de este trabajo, se analizarán aquellas expresiones que surgieron alrededor de la calidad del sonido en los recitales de rock en vivo, un asunto que fue preocupando de manera creciente a la crítica musical: la electrificación de instrumentos que supone el mismo género puso en evidencia las carencias técnicas, extensivas al resto de la música popular; los problemas de amplificación asociados a esta electrificación fueron permanente objeto de crítica; las deficiencias acústicas señalaron la falta de

\footnotetext{
Entre otros, Los Olimareños, Alfredo Zitarrosa y El Sabalero.

Acrónimo de Generación Ausente y Solitaria.

Sobre este conflicto generacional y el discurso de "orfandad" se puede consultar a Bayce (1989), Carbone y Forlán Lamarque (1987) y Muñoz y Del Signore (1991).

9 Michelle Phillipov (2006) advierte sobre la necesidad de distinguir entre género y cultura del rock, con el objetivo, entre otros, de advertir sobre eventuales incongruencias o no correspondencias entre uno y otra.

${ }^{10}$ Esta larga polémica es analizada en Brando (2012) y más en detalle en Farachio (2015).
} 
Austral Comunicación

Volumen 10, número 2 (Diciembre de 2021): 461-483 ISSN (I) 2313-9129. ISSN (E) 2313-9137

espacios adecuados para las nuevas manifestaciones musicales y, por extensión, para los nuevos públicos en formación.

A partir de estas asociaciones entre calidad de sonido y conformación de nuevos públicos surgen algunas preguntas que se van a intentar responder. ¿Qué exigían los músicos y críticos en términos de sonido? ¿Qué se entendía como una escucha "inadecuada" en los recitales de rock? A través de la discusión sobre los problemas de sonido, ¿se expresaban percepciones y concepciones sobre el público? ¿De qué tipo? ¿Qué dificultades o imposibilidades resultaban de una mala amplificación en términos de vivir la experiencia musical y, más allá, de comprender una nueva forma de socialización en el espectáculo en vivo? Además de señalar nuevas formas de vivir la experiencia musical, ¿la crítica se presentaba también como una dificultad para expresar la condición juvenil en la recuperación democrática?

Para responder estas preguntas, estudiaremos, en primer lugar, las posiciones de periodistas y músicos frente al uso de instrumentos eléctricos, los problemas de su acceso frente a las condiciones económicas y las estrategias de los músicos para trascender estas dificultades. Estos recursos les permitieron a los músicos expresarse en los términos exigidos por el rock como género, de acuerdo con elementos técnicos y performáticos particulares. En segundo lugar, analizaremos aquellas menciones de la crítica dirigidas a señalar, en los problemas de sonido, la presencia (o ausencia) de una "performance de autenticidad". Esta reflexión sobre la posibilidad (o no) de los grupos y músicos de presentarse como "auténticos" estuvo vinculada íntimamente con la calidad de la amplificación del sonido. Los problemas de amplificación serán los que van a impedir la conformación de este carácter "auténtico", problemas que finalmente serán interpretados por los periodistas como parte de una crisis del género. Por último, se analizarán las menciones de periodistas y músicos ante los problemas acústicos derivados de la precariedad de los recintos, los cuales señalan una dificultad para reconocer las características de los públicos juveniles en formación.

En términos generales, este análisis habilita a pensar en el sonido en términos de conflictos entre distintas expresiones de poder (y de resistencia al poder) que estaban revelándose en los primeros años de democracia. En otras palabras, no solo estaba cambiando la forma de comprender el género, a los jóvenes de la cultura rock y a su participación en tanto público consumidor. Esta mirada también ponía en discusión las formas de reunión de la juventud de los ochenta, sus formas de expresión, así como el interés que despertaba en el resto de la sociedad. Tal como explica Jacques Attali (1995):

Toda música, toda organización de sonidos es pues un instrumento para crear o consolidar una comunidad, una totalidad; es lazo de unión entre un poder y sus súbditos y por lo tanto, más generalmente, un atributo del poder, cualquiera que éste sea. Una teoría del poder exige pues actualmente una teoría de la localización del ruido y de su formación. 
Leandro Delgado, Federico Farachio

Eléctrico, auténtico y precario: el sonido y los nuevos públicos en los espectáculos de rock de los ochenta montevideanos

\begin{abstract}
Instrumento de demarcación de su territorio entre los pájaros, el ruido se inscribe, desde sus orígenes, en la panoplia del poder. Equivalente del enunciado de un espacio, indica los límites de un territorio, los medios para hacerse escuchar y para sobrevivir y obtener su alimento. Y por lo mismo que el ruido es fuente de poder, el poder ha estado siempre fascinado con su escucha. (p. 32)
\end{abstract}

Para este trabajo, se realizó un relevamiento exhaustivo de cuatro publicaciones diarias (El País, La República, Últimas Noticias y La Hora) y de cuatro semanarios del período (La Semana, Jaque, La Juventud y Aqui) sobre artículos referidos al rock en Uruguay entre 1984 y 1989, lo que suma un total de 208 artículos. Este período está definido, en el inicio, por las primeras notas referidas al género y, en el final, por la desaparición de la banda Los Estómagos, que marcó el fin de la etapa de resurgimiento del rock en Uruguay. Una segunda selección de 63 artículos de estas mismas publicaciones refiere específicamente a crónicas, críticas y entrevistas a músicos de rock y de la música popular, que presentan expresiones particulares sobre la instrumentación eléctrica, los problemas de amplificación y el comportamiento de los públicos.

\title{
La instrumentación eléctrica
}

Una primera señal de la importancia atribuida al sonido del rock en su relación con formas determinadas de vivir la experiencia musical y, más allá, con las formas de presentación de los jóvenes en la nueva democracia se puede encontrar en los inicios de 1986. En enero de ese año, el músico Jorge Bonaldi (1986) abrió el fuego iniciando una polémica que definiría, en gran medida, los términos de la discusión sobre el rock en Uruguay de allí en más.

A partir de la realización de recitales organizados por la Intendencia Municipal de Montevideo en escenarios callejeros, el músico rechazaba, entre otras críticas, las nuevas formas expresivas y performáticas del rock de los ochenta. En particular, la composición de canciones de rock en castellano era la confirmación del triunfo del imperialismo cultural estadounidense luego de once años de dictadura. En los sesenta, recuerda Bonaldi (1986), el imperialismo no había logrado consolidarse completamente, ya que las letras aún se cantaban en inglés. ${ }^{11}$

Lo relevante para este estudio es la crítica al uso de instrumentos eléctricos que el mismo género exige. Sin embargo, no refiere al sonido eléctrico de acuerdo con consideraciones estéticas, sino al elitismo que resultaba de la imposibilidad, de parte de la mayoría de los jóvenes, de acceder a instrumentos eléctricos dado su alto costo. Se trata de una crítica llamativa en el contexto de los ochenta, ya que habían existido

\footnotetext{
${ }^{11}$ La abundancia de referencias políticas y culturales de Bonaldi en su ataque al rock de los ochenta en esta crítica se alejan del tema específico del sonido. Su intervención presenta otras discusiones sobre el rock que trascienden los objetivos de este artículo.
} 


\section{Austral@municación \\ Volumen 10, número 2 (Diciembre de 2021): 461-483 ISSN (I) 2313-9129. ISSN (E) 2313-9137}

otras similares en las décadas anteriores tanto en Estados Unidos como en Brasil con bastante repercusión, es decir, la presencia novedosa de la instrumentación eléctrica era una señal de hegemonía cultural "exterior" sobre una cultura nacional. ${ }^{12}$

A esta altura, Bonaldi ya era un músico de sólida y amplia formación musical que incluía, no obstante, un pasado roquero. Así, su crítica retomaba esta misma formulación, aunque afirmando la posición "conservadora" frente a la electrificación. Se puede especular, entonces, sobre el conocimiento previo del debate fuera de fronteras sobre un tema sensible a las músicas populares nacionales, el cual empleó a su favor en los ochenta, ya que su música en particular, al momento del resurgimiento del rock, no presentaba elementos de rock reconocibles ni entendidos como expresión o parte de una cultura rock.

Pero, cuánto dinero cuesta la tecnología que se emplea para ponerlo en escena? Las re-
lucientes guitarras, los teclados, los equipos, las baterías electrónicas y las comunes, etc.,
cuestan mucho mucho dinero. O, en todo caso, bastante más del que puede ganar un uru-
guayo corriente de 17,18 o 19 años de edad. ¿Qué ocurre entonces? Sonará mejor quien
tenga más dinero. SE HARÁ OIR QUIEN TENGA MAYOR PODER ECONÓMICO. Ya
estamos otra vez frente al viejo problema de clases. ¿De qué sirve que un grupo de privi-
legiados económicamente desarrollen una manifestación de que luego la masa podrá par-
ticipar sólo como espectadora por falta de medios? Eso, aquí en Latinoamérica, es cultura
de élite, o de clase. En Europa no, pero aquí sí. (Bonaldi, 1986, s.p.) ${ }^{13}$

El énfasis de la cita no solo subraya el resurgimiento del rock como una manifestación juvenil en términos de clase. También considera el acceso a la instrumentación eléctrica como una acentuación de la distancia entre artistas y espectadores, distancia que no será discutida aquí. Lo relevante para este análisis es observarla en el contexto de la conversación en la prensa sobre el uso de instrumentos eléctricos. Si bien la mayoría de los jóvenes de los ochenta no podían acceder a su compra, ellos mismos establecieron prácticas y usos que lograban trascender las dificultades económicas de acuerdo con formas de socialización y de vivir la experiencia musical. Se trataba de experiencias compartidas tanto por jóvenes músicos con escasa trayectoria como por los grupos consagrados dentro de la escena roquera.

Un ejemplo del primer caso es la Cooperativa del Molino, un colectivo artístico de formación espontánea e impronta anárquica que se reunía habitualmente en la zona del Molino de Pérez, un parque público situado alrededor de una construcción del siglo XVIII (un molino) sobre la costa de Montevideo, entre los barrios residenciales de Malvín y Punta Gorda. Allí se reunieron grupos como Clandestino, Post Coito, Orgasmo Rosa, Las Tumbas y Sádica, entre otros, que no pertenecían al mainstream

\footnotetext{
${ }_{12}$ Estos fueron los casos, por ejemplo, de Bob Dylan, mencionado en Gracyk (1996), y de Caetano Veloso (1997) cuando ambos fueron criticados por el público en sus primeras presentaciones "eléctricas".

${ }^{13}$ Mayúsculas de Bonaldi.
} 
Leandro Delgado, Federico Farachio

Eléctrico, auténtico y precario: el sonido y los nuevos públicos en los espectáculos de rock de los ochenta montevideanos

roquero del momento (Blister Doc, 2014). Se trataba de un espacio que carecía de un escenario definido y donde los integrantes de las bandas compartían e intercambiaban no solo instrumentos, sino también integrantes, quienes oscilaban entre bandas de punk rock y heavy metal. Ocasionalmente se empleaba, de manera ilegal, la electricidad del alumbrado público (Blister Doc, 2014).

Con respecto a los grupos consagrados, son ilustrativas las declaraciones de Los Tontos, banda que, en la segunda mitad de la década, se convirtió en una de las más escuchadas y difundidas. ${ }^{14}$ En varias de sus entrevistas presentan un conocimiento de las condiciones de sonido que les permitió superar las adversidades de amplificación y acústica. Para la grabación de su primer disco -Los Tontos (1986)- debieron conseguir prestada una cantidad considerable de instrumentos eléctricos, la cual dependía de la disponibilidad existente al momento de cada sesión de grabación.

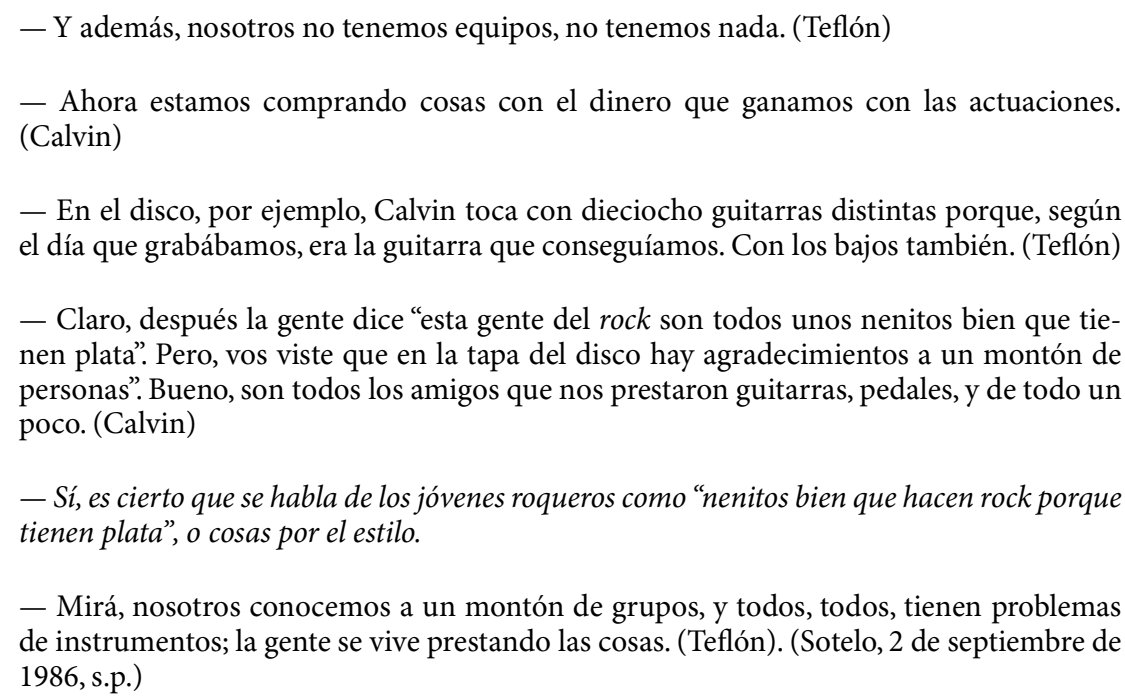
nen plata". Pero, vos viste que en la tapa del disco hay agradecimientos a un montón de personas". Bueno, son todos los amigos que nos prestaron guitarras, pedales, y de todo un poco. (Calvin)

- Sí, es cierto que se habla de los jóvenes roqueros como "nenitos bien que hacen rock porque tienen plata", o cosas por el estilo.

- Mirá, nosotros conocemos a un montón de grupos, y todos, todos, tienen problemas de instrumentos; la gente se vive prestando las cosas. (Teflón). (Sotelo, 2 de septiembre de 1986, s.p.)

Los músicos parecen responder directamente a la crítica de Bonaldi (1986) sobre "el viejo problema de clase", manifiesto en el acceso desigual a la instrumentación eléctrica. El préstamo e intercambio de guitarras, bajos y pedales no solo cuestionan la crítica inicial, sino que presenta, de parte de los músicos, formas de autogestión extensivas a otras bandas de rock que no parecen ser detectadas ni previstas por la crítica.

En ambos ejemplos se trata de formas autogestionarias y espontáneas que lograron superar los obstáculos económicos. En otras palabras, los vínculos afectivos, de confianza y de solidaridad generacional les permitieron a estos jóvenes acceder al

${ }^{14}$ Los Tontos fue una banda de breve trayectoria, pero de gran impacto en la cultura del momento debido, en gran medida, a sus letras irreverentes, a su explosiva masividad y a la conducción de un programa de televisión dedicado al rock, conocido como La Cueva del Rock, en Canal 4. 


\section{Austral Omunicación \\ Volumen 10, número 2 (Diciembre de 2021): 461-483 ISSN (I) 2313-9129. ISSN (E) 2313-9137}

equipamiento imprescindible. Los usos particulares que los músicos pudieron hacer, en especial los préstamos e intercambios, no solo habilitan a comprender las estrategias específicas llevadas adelante, sino también a entender estas estrategias como formas horizontales de cooperación que trascienden la mera división entre producción y consumo. En otras palabras, estas formas de "supervivencia" frente a condiciones económicas dominantes y adversas habilitaban a los músicos a emplear los productos creados e impuestos por el orden económico denunciado por Bonaldi (1986), de acuerdo con formas inesperadas y creativas que existieron en la instancia de consumo (de instrumentos).

Es importante vincular este comportamiento de los músicos y las nuevas formas de consumo con el planteo de Michel de Certeau (1998) acerca de las estrategias de consumo particulares, casi invisibles, frente a la "espectacularidad" de la producción de bienes, estrategias que permiten trascender la pasividad y el lugar fijo atribuido a los consumidores. En otras palabras, este comportamiento de consumo activo y selectivo -en este caso, fundado sobre redes afectivas y de afinidad- les permite a los músicos no solo sortear los obstáculos para participar de la producción de bienes (discos, en este caso), sino también ofrecerles agencia en un contexto de mercado definido por las demandas de la competencia y, siguiendo a Attali (1995), formar comunidad.

\section{La performance de autenticidad}

La discusión sobre los problemas de la amplificación en espectáculos en vivo es creciente en las crónicas, críticas y entrevistas. Estos problemas parecen ser determinantes en la aparición de la presunta "crisis" de un género cuyo renacimiento había ocurrido solamente unos años antes. Para abordar su análisis, presentamos una discusión sobre las características del propio género en términos, en primer lugar, de su estatus de "autenticidad"; segundo, del componente eléctrico y tecnológico que hace al género posible; y tercero, de la correspondencia paradójica o contradictoria que existe entre su carácter "auténtico" y, al mismo tiempo, mediado tecnológicamente. Según lo expresado en críticas y entrevistas, los problemas de sonido les habrían impedido a las bandas, o al menos dificultado, presentarse como "auténticas", dificultad que se hace extensiva a la "crisis" mencionada.

En su estudio sobre rock y performance, que abarca el desarrollo del rock desde su surgimiento hasta la primera década del siglo XXI, David Pattie (2007) presenta la distinción constante entre el carácter "comercial" del género y la "autenticidad", atributo este que determinaría, para el caso del rock, la calidad de una canción, disco o artista (p. 5). Se trata, sin embargo, de una distinción ilusoria o construida, explica, desde que el rock también se encuentra sometido a presiones comerciales, como sería el caso de los sellos discográficos. 
Leandro Delgado, Federico Farachio

Eléctrico, auténtico y precario: el sonido y los nuevos públicos en los espectáculos de rock de los ochenta montevideanos

Para el autor, el lenguaje de la autenticidad en la performance roquera se manifiesta a través de una serie de tropos: "Gestos, poses, tonos característicos e imágenes los cuales, en los ojos del público, sugieren metafóricamente la presencia de un performer auténtico" (Pattie, 2007, p. 13). En definitiva, la pregunta fundamental acerca de la autenticidad (tanto para el intérprete como para la audiencia) parece ser una cuestión de fe:

\begin{abstract}
La expresión espontánea de la fe de la audiencia y del intérprete en el acto parece, al menos para algunos artistas, confirmar que la conexión entre el intérprete y la audiencia puede ser denominada auténtica, no importa cuán transparentemente falsas sean las trampas de la actuación. (Pattie, 2007, p. 11)
\end{abstract}

Por su parte, Allan Moore (2002) plantea que, en el discurso de la cultura del rock, el término "autenticidad" se ha empleado para definir un "estilo" de escritura de canciones o de performance, es decir, la presencia de cualquier elemento asociado con las prácticas del vocalista o del músico en las que son importantes algunos elementos como la "intimidad" o la "inmediatez", en este último caso, entendiendo formas de producción musical "no mediadas" (unmediated) (p. 211). Este elemento tiene singular importancia para nuestro análisis, como se verá más adelante. Asimismo, en un sentido "socioeconómico", el término se emplea para determinar las eventuales razones por las que un músico realiza su trabajo: sea para sí mismo, para su propia música, para su público o "para su cuenta bancaria" (p. 211). En otro sentido, la autenticidad también refiere a la posibilidad de adquirir modos "auténticos" de expresión respecto a otras bandas o músicos tomados como referencia y que adscriben a una tradición de performance "auténtica", que puede ser observada, por ejemplo, en la reinterpretación del blues del delta del Mississippi de comienzos del siglo XX por el movimiento de blues inglés de los sesenta.

Es relevante para este trabajo la sistematización que realiza Moore (2002) sobre tres tipos de autenticidad en la música popular contemporánea y en el rock en particular. Una autenticidad de primera persona, también denominada "autenticidad de expresión", ocurre cuando el compositor o intérprete logra que su enunciado sea uno de "integridad" y representa un intento de comunicación "no mediada" con un público (p. 214). Una autenticidad de segunda persona, o "autenticidad de la experiencia", tiene lugar cuando la performance logra transmitir la impresión de que la experiencia de vida del oyente es válida y que esa experiencia puede ser contada "tal como es" (p. 220).$^{15} \mathrm{La}$ autenticidad de tercera persona, o "autenticidad de ejecución”, surge cuando el intérprete

\footnotetext{
15 Un ejemplo de la autenticidad de segunda persona es expresada por Gabriel Peluffo, vocalista de Los Estómagos: "Algo que quiero decir es que nosotros no establecemos una diferencia entre lo que es el músico y lo que es el público; nosotros somos jóvenes uruguayos que tenemos necesidad de expresarnos, formamos un grupo de rock y hacemos y decimos lo que sentimos. Es un fenómeno que surge de la misma juventud que nos va a ver" (como se citó en Sotelo, 11 de marzo de 1986, s.p.).
} 


\title{
Austral Omunicación \\ Volumen 10, número 2 (Diciembre de 2021): 461-483 ISSN (I) 2313-9129. ISSN (E) 2313-9137
}

logra representar, de manera precisa, las ideas de otros músicos que pertenecen a una tradición de performance (p. 218).

Se trata entonces de comprender la adjudicación de autenticidad como una suerte de integridad o como una exhibición de "realismo", de ausencia de pretensión o de exhibición, aun cuando estos atributos evoquen una tradición existente que ha exhibido los mismos rasgos. En cualquier caso, es importante considerar que todas estas adjudicaciones no se excluyen unas a otras, sino que están en permanente tensión (Moore, 2002, p. 211). En definitiva, la autenticidad es un elemento principal de la performance que se presenta en construcción permanente y nunca como algo finalizado o completo (Pattie, 2007, p. 7). Ejemplos de todos estos rasgos - presentes de manera contradictoria- se pueden observar en el breve pasaje de una reseña crítica sobre el primer disco de Los Estómagos, Tango que me hiciste mal (1986).

\begin{abstract}
Aquí están Los Estómagos: rock duro, letras duras (y que a veces son trazos gruesos, porque no han sido trabajadas) y "algunas deudas" con los grupos gringos ya mencionados, pero, sin duda, muy auténticos y con la vitalidad de una propuesta nueva. Ni cortos ni perezosos, los ejecutivos de la empresa argentina Interdisc ya les hicieron un contrato en exclusiva por cinco años. [...] No sé qué dirección habrá de tomar el grupo, tampoco ellos lo saben. [...] Los Estómagos, la cresta visible de una ola rockera con muchos adeptos, a pesar de la "insolencia" de sus jopos tiene un nivel de modestia real. Esos amigos míos, que en el 83 me hablaban del grupo, me cuentan (ahora que los escucho en cassette) que Los Estómagos son mucho más fuertes en vivo que en grabaciones. (Pérez da Cunha, 1985, s.p. $)^{16}$
\end{abstract}

En la adjetivación empleada para hablar de las letras, entendidas como "duras" o "trazos gruesos", estaría justificado, incluso, el presunto poco trabajo dedicado a su composición, dado que lo relevante sería el carácter inmediato o, de otra forma, no mediado de la interpretación, que estaría ofreciendo, de forma directa, una "vitalidad" que sería la base del carácter auténtico. No resulta contradictorio, en esta misma crítica, el carácter explícitamente auténtico junto con el carácter comercial que surge con la firma del contrato con la empresa argentina, subrayando así la tensión constante entre ambas actitudes. Esta construcción permanente de la autenticidad del grupo se ve acentuada al mencionar, en palabras de los músicos, la confesión de la incertidumbre sobre sus pasos futuros. De esta forma, lo auténtico se expresa en el carácter aparentemente errático en tanto expresión espontánea frente a su propia obra.

Estos rasgos de autenticidad se ven reforzados por las confesiones de los propios músicos. En la entrevista a Los Tontos, estas señales se repiten no solo en el manejo de un habla "espontánea", sino también en las formas espontáneas, no mediadas o no establecidas (de acuerdo con criterios comerciales), de concebir tanto la grabación de

16 Énfasis nuestro. 
Leandro Delgado, Federico Farachio

Eléctrico, auténtico y precario: el sonido y los nuevos públicos en los espectáculos de rock de los ochenta montevideanos

discos como de la performance musical. La pregunta del periodista va dirigida claramente en esa dirección.

- Otra característica del material del disco es la falta de rebuscamientos en los arreglos; en general todos los temas tienen un sonido más bien crudo, sin rebuscamientos.

- Sí, nosotros podríamos haber hecho temas mucho más arreglados, mejores armónicamente. Lo nuestro es así, la onda no es que digan "mirá qué arreglos". La onda es que se haga algo muy fresquito. (Calvin)

- Apelamos a la simpleza, a la sencillez en el producto. En el disco se tocó igual que en el escenario. (Teflón)

- Nosotros vamos a algo que sea directo, y que sea, bueno, que sea bailable. Claro que vos podés hacer música muy arreglada y bailable también, pero a nosotros nos gusta hacerla así; no pretendemos trascender como grandes músicos ni nada. (Calvin)

- Y además tratamos de no usar en el estudio instrumentos que después no vamos a poder usar en vivo. (Teflón). (Sotelo, 2 de septiembre de 1986, s.p.) ${ }^{17}$

Además de las coincidencias con la cita previa en cuanto a la sencillez de los arreglos, ${ }^{18}$ se presentan dos elementos que vale mencionar. En primer lugar, surge la confesión explícita de una falta de pretensiones de los músicos más allá de la composición de sus canciones, es decir, sin ningún afán de trascendencia. En segundo lugar, la construcción de un "discurso" de autenticidad le permite a la banda explicar su lugar en la escena musical del momento. Renzo Teflón, vocalista de la banda, insiste en señalar que esa frescura y espontaneidad que manifiestan en sus discos era posible de trasladar al escenario porque tocaban con la misma instrumentación, escasa y accesible, empleada en la grabación. Se trata de una observación muy lúcida del músico, que interpreta, como ya se vio, el contexto económico empobrecido en el que surgieron las nuevas bandas y las formas de encarar y reunir los escasos recursos disponibles. ${ }^{19}$ La observación es valiosa porque también permite indagar, a continuación, en los problemas de amplificación que expresaron tanto músicos como críticos y en una crisis del género que sobrevendría como consecuencia.

\section{Problemas de sonido}

Los problemas de amplificación son mencionados principalmente a partir de Montevideo Rock 1, espectáculo de grandes dimensiones que reunió bandas argen-

17 Énfasis nuestro

${ }_{18}$ En términos generales, la sencillez de los arreglos también era parte de las características del punk rock como género, que reaccionaba de esta forma a las derivaciones sinfónicas y a los despliegues de virtuosismo característicos del rock progresivo (Marcus, 1993).

19 El afán de sonar como en el estudio refiere también a una característica esencial del género: el rock entendido como una tradición de la música popular cuya creación y diseminación se centra en la tecnología de grabación (Gracyk, 1996). 


\section{Austral Omunicación \\ Volumen 10, número 2 (Diciembre de 2021): 461-483 ISSN (I) 2313-9129. ISSN (E) 2313-9137}

tinas, uruguayas y brasileñas y que fue considerado un hito de la cultura rock de ese período.$^{20}$ Las reseñas abundan en críticas a los problemas de amplificación de las bandas uruguayas, que los periodistas adjudicaban a la mala fe de los técnicos argentinos a cargo de todo el espectáculo, quienes habrían perjudicado deliberadamente a los artistas uruguayos (Anchustegui, 1986; Iglesias, 1986a, 1986b).

La diferencia de sonido entre las presentaciones de bandas uruguayas y argentinas se puede atribuir a la diferencia en las dimensiones de las industrias musicales de ambos países. Aunque las dictaduras coincidieron en el tiempo a ambos lados del Río de la Plata, así como en la represión al rock de su tiempo, se puede señalar, en primer lugar, que la dictadura argentina fue sensiblemente más breve (8 años) que la uruguaya (13 años). En segundo lugar, a partir de la guerra de Malvinas -a comienzos de 1982 entre Argentina y Gran Bretaña-, el Gobierno argentino prohibió la difusión de música en inglés y promovió las bandas nacionales que había censurado hasta hacía poco (Anguita y Cecchini, 2020, s.p.), estimulando de manera considerable la producción nacional. Esta continuidad del rock argentino frente a la interrupción casi completa del rock uruguayo podría explicar, en parte, la continuidad de una tradición musical de rock argentino y, por lo tanto, de una mayor formación por parte de sus sonidistas.

Las críticas a la amplificación arreciaron un año después con el surgimiento de otros espectáculos de grandes dimensiones, uno en el Teatro de Verano y otro en el Palacio Peñarol. En este último caso, las condiciones acústicas de ese estadio cerrado de básquetbol no solo ponían en evidencia la falta de previsión y el descuido en los aspectos tecnológicos, sino específicamente en las carencias en la calidad de la amplificación. Estas carencias tuvieron consecuencias directas en la misma concepción -de parte de los periodistas- del advenimiento de una crisis o del simple fracaso del rock uruguayo entendido como "movimiento". Para analizar mejor estas reflexiones, es necesario hacer algunas precisiones del género respecto a la amplificación eléctrica.

Theodore Gracyk (1996) señala cómo la amplificación de la guitarra eléctrica no genera simplemente un sonido con volumen alto, sino un nuevo tipo de sonido, el cual ha venido siendo "explotado" por los músicos del rock de acuerdo con sus propuestas expresivas (p. 110). En otras palabras, no se trata de hacer sonar los instrumentos de manera amplificada para ser escuchados por grandes cantidades de público, sino también porque el volumen en el rock tiene un papel central tanto en la composición y en la reproducción (p. 110) como en la interpretación en vivo. En el caso particular de la guitarra eléctrica, este instrumento se presenta como el elemento estético central del gé-

\footnotetext{
${ }^{20}$ La primera edición del Montevideo Rock se realizó el 21, 22 y 23 de noviembre de 1986 en La Rural del Prado. Reunió a solistas y bandas de cuatro países: los argentinos Sumo, Fito Páez, La y GIT; los brasileños Os Paralamas do Sucesso y Legiâo Urbana; los chilenos Los Prisioneros Torre y Valija Diplomática, y los uruguayos Alvacast, Los Estómagos, Los Tontos, José Pedro Beledo, Zero, Los Traidores, Neoh 23, La Tabaré Riverock Banda, Cuarteto de Nos, Zaffaroni, Fernando Cabrera, Cross y Ácido. Se calcula una asistencia total de 45000 jóvenes.
} 
Leandro Delgado, Federico Farachio

Eléctrico, auténtico y precario: el sonido y los nuevos públicos en los espectáculos de rock de los ochenta montevideanos

nero dadas sus posibilidades de presentar sonidos, timbres y técnicas específicas (p. 111). El bajo eléctrico presenta un caso similar en cuanto a la condición excluyente de la amplificación. Lo mismo puede decirse del uso de los micrófonos y de la propia amplificación, en ambos casos, con fines expresivos (p. 109).

En los términos en los que venimos analizando, estos fines expresivos están dirigidos a completar en el espectáculo en vivo una performance de autenticidad que no alcanza con gestos, poses o formas de presentación frente al público. El papel central que juega aquí la amplificación permite desplegar los recursos mencionados para expresar "honestidad", "sencillez" "realismo" o "espontaneidad", es decir, recursos que no serían posibles construir, en principio, sin una amplificación efectiva. En este punto, es importante recordar también, como característica de la performance "auténtica", el carácter "inmediato" o "no mediado" o, mejor dicho, la apariencia de un carácter "no mediado".

De esta forma -parece surgir del análisis de las crónicas-, los defectos en la amplificación del sonido estarían poniendo de manifiesto no solo la precariedad de la performance, sino también su carácter mediado, su dependencia de una tecnología que se presenta más como un obstáculo y menos como recurso expresivo. En definitiva, esta revelación de la mediación no solo rompe el compromiso de autenticidad que establece el público hacia los intérpretes mencionado por Moore (2002), sino que obstaculiza toda otra expresión de autenticidad. Sobre el recital en el Palacio Peñarol, el periodista Raúl Forlán Lamarque (2 de septiembre de 1987) se lamentaba en una crónica titulada "Rock en el Palacio: un sonido lamentable" de la siguiente manera:

\begin{abstract}
Salvo Los Traidores, que en algún momento de su set estuvo sinceramente balanceada su sonoridad, los restantes grupos fueron caricaturas tratando de comunicarse y fundirse con el público. La guitarra chirriante, ulular [sic] de Pablo Rhodas (el estupendo instrumentista de Neoh 23), era una especie de trompada en la cabeza. En ningún momento del show -y dejando de lado la excepcionalidad de Los Traidores- hubo limpieza expositiva y equilibrio en el espesor expresivo de cada instrumento.

$[\ldots]$

El Puti Club, por ejemplo, que debutaba en un espectáculo de característica multitudinaria, fue apenas una entusiasta intención de ska y de reggae a causa de las deficiencias de sonido. Pero, asimismo, ¿quién estuvo al frente de la consola? Se evidenciaron serios errores, y al parecer, quien manejó el monitoreo y el despegue de sonido estaba al borde de la sordera. O bien no se puede contra lo ya constatado en relación al Palacio Peñarol, o los sonidistas no se esforzaron lo debido para mejorar, en la medida de lo posible, la amplificación. En fin... (s.p. $)^{21}$
\end{abstract}

La crítica revela con más claridad el nexo entre amplificación y la performance de autenticidad. La presentación de los músicos como "caricaturas" parece dar cuenta, de parte de las bandas, de un despliegue de gestos y movimientos característicos de la

21 Énfasis nuestro. 


\section{Austral Omunicación \\ Volumen 10, número 2 (Diciembre de 2021): 461-483 ISSN (I) 2313-9129. ISSN (E) 2313-9137}

performance de rock que no estarían acompañados de un sonido que completara la expresión "auténtica", poniendo en cuestión la autenticidad de primera persona señalada por Moore (2002). La imposibilidad metafórica de "fundirse con el público" refiere, a su vez, a la imposibilidad de una identificación con los oyentes a través de una fidelidad sonora, inhabilitando de esta forma la autenticidad de segunda persona, también mencionada por Moore (2002).

La imposibilidad o dificultad para establecer una correspondencia entre el sonido y la performance resulta finalmente en un diagnóstico pesimista de la crítica sobre una presunta crisis. En otras palabras, el rock no sería posible de proyectarse hacia el futuro de no existir la tecnología sonora adecuada ni las condiciones acústicas mínimas para desarrollarse. El mismo Forlán Lamarque (24 de junio de 1987) presenta las causas de esta eventual crisis, que se manifiesta, en principio, por un desbalance entre la numerosa presencia de bandas de rock en las nuevas radios de $F M,{ }^{22}$ por un lado, y la escasez de espectáculos en vivo, por otro; es decir, en la incapacidad de una infraestructura de producción en vivo que no lograba incorporar a todas las bandas. ${ }^{23}$ Otra causa importante, señala Forlán Lamarque (9 de septiembre de 1987), proviene de que los empresarios no tenían en cuenta aspectos básicos del sonido en vivo ni el interés de considerarlos.

En fin, quiero decir que los músicos se vuelven indefensos, y ante la contratación de un parque sonoro insuficiente o deficiente, las apariciones de éstos en escena los regresa al rincón del amateurismo. En ese sentido, los citados paracaidistas jamás darán la cara, no se responsabilizarán por el espeluznante sonido que particularizó la velada, pasarán por boletería a recoger el dinero recaudado y que, por favor, nadie los acuse de la desestructurada estructura que contracturó el sentido del espectáculo.

[...]

En fin, debemos decidirnos a defender lo que nos pertenece. Así es: la música tanto de Zitarrosa como la de la Tabaré Riverock Banda, nos identifica, nos enmarca, nos delimita, nos libera y nos potencia. De continuar ese disgusto de las malas amplificaciones sería como condenar esa música a una suerte de exilio, de despertenencia. Y creo que nadie lo desea. (p. 16) 24 $^{24}$

El periodista ubica al rock de los ochenta en una zona liminar situada fuera y dentro de la música popular. Al mismo tiempo que lo considera como parte de una tradición musical que lo emparentaba con músicos clave de esta tradición, menciona que corre el riesgo de no ser incluido, justamente porque las condiciones tecnológicas no lo habilitarían -dadas las exigencias del género- a alcanzar su estatus cultural en los tiempos que corren. No se trata, sin embargo, de un reclamo aislado, ya que son nume-

\footnotetext{
${ }^{22}$ Sobre el final de la dictadura, el Gobierno habilitó 53 ondas de FM, en las que existieron programas clave para el desarrollo de la música rock en Uruguay (Rodríguez, 2012).

${ }^{23}$ Guillermo Baltar (1986) también señala este desbalance, que se reflejó en graves problemas de seguridad en un festival de rock en el Teatro de Verano.

${ }^{24}$ Énfasis nuestro.
} 
Leandro Delgado, Federico Farachio

Eléctrico, auténtico y precario: el sonido y los nuevos públicos en los espectáculos de rock de los ochenta montevideanos

rosas las discusiones en estos mismos años cuando se disputaba el lugar del rock en la tradición musical uruguaya (Brando, 2012; Farachio, 2015). En cualquier caso, se puede reflexionar acerca del diagnóstico de esta crisis como un elemento paradójicamente constitutivo del rock de los ochenta, según se analiza a continuación. ${ }^{25}$

Tal como fue presentado en palabras de Moore (2002), la performance de autenticidad exigida por el rock se encuentra, por definición, en construcción permanente o en una tensión constante y aparente entre lo "auténtico" y lo "comercial". Al mismo tiempo, Pattie (2007) explica que "la autenticidad en el rock ha existido siempre en crisis" (p. 6), una crisis que se infiere como extensiva a todo el género. De esta forma, parece extenderse, en nuestro caso, a toda la cultura rock montevideana, que venía elaborando un discurso para sí misma en el que se ponían en juego tanto su pertenencia a la tradición musical y cultural como su propia viabilidad en un contexto de crisis económica y de rechazo generacional tanto por parte de los mayores como de la izquierda cultural, como fue señalado en la presentación del discurso de "orfandad".

En efecto, la idea de una crisis en el rock, a solo cuatro años de su renacimiento oficial, permitía, paradójicamente, reeditar el discurso de orfandad que la generación había logrado construir para sí misma, logrando de esta forma volver a poner el rock en escena. No obstante, existieron problemas reales de amplificación y los diversos testimonios permiten pensar hasta dónde el discurso de "generación ausente y solitaria" operaba de forma contradictoria, pues al tiempo que afirmaba la cultura rock en el plano de las identificaciones, la alejaba de una tradición a la que intentaba pertenecer.

\section{El público y los públicos}

Los problemas referidos a las condiciones físicas y espaciales de los recintos son también motivo de críticas frecuentes, las cuales remiten, en última instancia, a señalar nuevas conformaciones de públicos de acuerdo con una fragmentación visible en diversos ámbitos de la cultura (Delgado, 2014). Este vínculo entre recintos y públicos en principio resulta evidente, pero pone en escena tanto la precariedad de los espacios y la escasez de lugares disponibles para espectáculos de rock como las concepciones dominantes del público -de parte de periodistas, empresarios y músicos- en términos de sus dimensiones e intereses.

\footnotetext{
${ }^{25}$ Los problemas de sonido no se limitaron a los espectáculos de rock, sino también a otras manifestaciones de la música popular. Es significativo el nombre de un espectáculo del músico Jorge Lazaroff en ese mismo período, denominado "Medio kilo de luces y sonido", en el que el entrevistado aclara que el medio kilo solo corresponde a la iluminación, ya que la presentación no prevé amplificación. (Jorge Lazaroff: mucho más de..., 1986, p. 2). Quedaría para otro trabajo indagar en los problemas de sonido que estos músicos tuvieron en el mismo período, así como la vinculación indudable con el rock de los músicos surgidos en el contexto del canto popular, tales como Jaime Roos, Fernando Cabrera, Eduardo Darnauchans o el mismo Lazaroff.
} 


\section{Austral Comunicación \\ Volumen 10, número 2 (Diciembre de 2021): 461-483 ISSN (I) 2313-9129. ISSN (E) 2313-9137}

En el conjunto de los artículos relevados parece haber una suerte de confusión acerca de las conformaciones, las fracturas y los desplazamientos de estos públicos. Por un lado, los músicos señalan la necesidad de acceder a las pequeñas salas céntricas, a diferencia de las presentaciones en locales improvisados en barrios periféricos de la ciudad, características del período del canto popular. ${ }^{26}$ Por otra parte, se daba por hecho un desplazamiento del público desde los grandes espacios hacia las pequeñas salas. ${ }^{27}$ No obstante, el festival Montevideo Rock, en la Rural del Prado, reinauguró un año después la tendencia de espectáculos multitudinarios, afirmada en su segunda edición de en el estadio Luis Franzini, en 1987, y en otros de igual convocatoria en el Velódromo Municipal, en el Teatro de Verano y en el Palacio Peñarol, además de recitales al aire libre organizados por la Intendencia Municipal de Montevideo, en los que también participaron músicos de distintos orígenes y generaciones.

Dadas las dimensiones de los espectáculos, es posible pensar que las concepciones del público, de parte de sectores de la prensa, remitían a aquellas que provenían de los recitales pasados de canto popular, es decir, un público de grandes dimensiones que se comportaba de manera homogénea y sin presentar mayores "negociaciones" en cuanto a la propuesta de los músicos en el escenario. ${ }^{28}$ Son numerosas las quejas de músicos y periodistas respecto a las decisiones empresariales que tomaban como referencia el modelo de "espectáculo multitudinario" del canto popular para trasladarlo a los recitales de rock en grandes espacios, con los consecuentes problemas acústicos. Las exigencias del género -su naturaleza eléctrica y amplificada- no encontraba en estos recintos las condiciones acústicas mínimas, que se sumaban a los problemas de amplificación. ${ }^{29}$

En las reseñas críticas, resulta claro que la responsabilidad recae en las malas decisiones de los empresarios, quienes simplemente habrían orientado el interés hacia el género mientras conservaban los mismos recintos del pasado. Es significativa también la ausencia de los nombres de estos empresarios en todas las notas, como si operaran

${ }_{26}$ Sobre la necesidad de recintos adecuados, el músico Leo Maslíah explica: "Si vos vas a tocar a una cooperativa de viviendas o a un local improvisado, y si las condiciones acústicas y de amplificación son muy malas, por más que vos te esfuerces en ir a tocar a los barrios, la gente no va a poder percibir lo que hacés" (como se citó en Sotelo, 11 de marzo de 1986, s.p.).

27 Un año antes de la entrevista a Maslíah, el mismo Sotelo (1985) expresaba: "Los espectáculos multitudinarios, que antes se sucedían semana a semana, ahora puede decirse que pertenecen al pasado, o al menos se dan con una frecuencia normal. La tónica la vienen dando los recitales en pequeñas salas, una modalidad muy apreciada por la mayoría de los cantores uruguayos, por sumar a sus ventajas organizativas, un grado de comunicación con el público muy superior" (s.p.).

28 Empleamos el término "negociación” a partir de la definición de Stuart Hall (1980) y la lectura "negociada" en la instancia de recepción, es decir, aquella en la que se acuerda "la posición privilegiada con las definiciones dominantes de los acontecimientos mientras se reserva el derecho de hacer una aplicación más negociada a las 'condiciones locales"' (138).

29 "El Palacio Peñarol -y ya lo sabemos de sobra- no fue pensado para espectáculos musicales y sin embargo se insiste en su contratación para mandar al matadero a los músicos. Queremos pensar que ese espacio es una especie de rockódromo, y más tarde, cuando ya nadie puede revertir la situación, empezamos a bordear la irritación y la impotencia en tomo [sic] de puteada" (Forlán Lamarque, 2 de septiembre de 1987, s.p.). 
Leandro Delgado, Federico Farachio

Eléctrico, auténtico y precario: el sonido y los nuevos públicos en los espectáculos de rock de los ochenta montevideanos

"en la oscuridad" y con el solo objetivo de obtener ganancias sin ninguna consideración por la calidad del sonido. Sin embargo, a pesar de estas críticas, los periodistas parecen compartir, junto con las decisiones empresariales, la concepción de un público, si no multitudinario, al menos homogéneo en cuanto a expectativas e intereses. Así se refleja en la reseña crítica de Forlán Lamarque (2 de septiembre de 1987) sobre el recital en el Palacio Peñarol.

\begin{abstract}
En otro orden: ¿qué pasa con el público? Porque salvo las quinientas o seiscientas personas que se arremolinaron con sana euforia contra el escenario, el grueso del público estaba con la mente en Hiroshima, en cómo armar un meccano [sic] tamaño baño. Eso lo advertimos no sólo algunos periodistas presentes sino también público en general y asimismo músicos como Gabriel Peluffo que, con profunda tristeza, me lo confesó horas después del espectáculo. Creo, sencillamente, que a esta altura al público le da lo mismo ir a un espectáculo de música rock o a ver mugir bovinos en una tarde soleada de la Rural del Prado. El público, globalmente hablando, no demuestra ni compromiso ni interés para con la corriente de rock. Va al Palacio Peñarol, charla con los amigos de ocasión, bebe refrescos, juegan a identificar a los agentes de la brigada de narcóticos y se va a dormir porque mañana, como dicen magníficamente Los Traidores, "será un día más". (s.p.) $)^{30}$
\end{abstract}

En términos de la dificultad para detectar las conformaciones de los públicos en formación, la cita habilita varias interpretaciones. En primer lugar, se puede apreciar la imposibilidad o la dificultad para aceptar la fragmentación mencionada. Por un lado, están las quinientas o seiscientas personas "comprometidas" con el espectáculo (junto al escenario) y, por otro, está el resto, que no logra ser definido con precisión: "el grueso del público", "público en general" y "el público, globalmente hablando". La dificultad para aceptar esta fragmentación surge de una apreciación que resulta difícil de comprender en la actualidad, es decir, considerar que seiscientas personas puedan ser escasas para un espectáculo de rock en Uruguay, una escasez que estaría definida, en este caso, en función de las dimensiones del recinto y del carácter de festival que suponía la participación de varios grupos.

En segundo lugar, parece existir una dificultad para comprender que los distintos públicos que ocupaban el mismo recinto podían tener diferentes intereses en un mismo evento, tanto por la presencia de bandas distintas como por la actitud frente a la escucha, por momentos más o menos concentrada en la performance. El periodista extraña una falta de "compromiso" de parte del público, lo cual evoca de manera inevitable el compromiso político que pudieron tener los asistentes a los espectáculos multitudinarios de canto popular. En tercer lugar, la mayor dificultad radica en comprender que existían diferentes formas de asistir y de participar de un evento musical, el cual implicaba instancias de socialización en las que la música operaba también como factor aglutinante.

30 Énfasis nuestro. 


\section{Austral Comunicación \\ Volumen 10, número 2 (Diciembre de 2021): 461-483 ISSN (I) 2313-9129. ISSN (E) 2313-9137}

En este aspecto, parecen ser los músicos quienes percibieron con mayor claridad la fragmentación de un público homogéneo y la conformación de nuevos públicos con intereses distintos. En una entrevista a los integrantes de Los Tontos, Trevor Podargo señala con elocuencia los comportamientos de distintos públicos que resultaban, en la misma instancia de recepción, mucho más activos que aquel que recibía pasivamente un "mensaje".

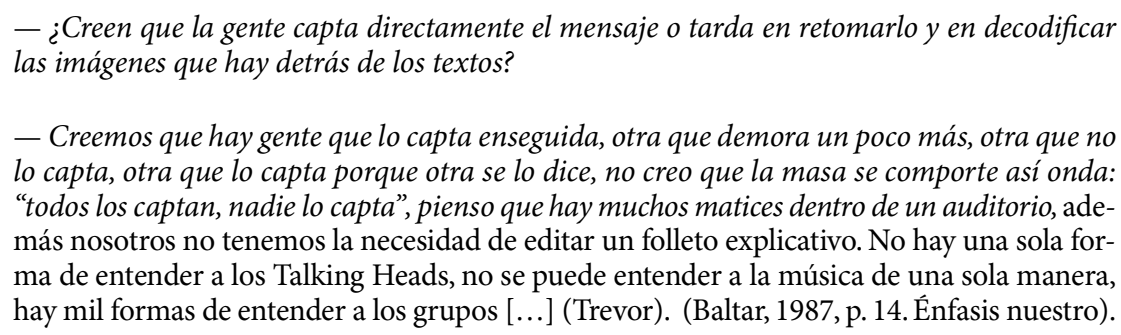

La pregunta del periodista va dirigida a comprender la recepción de un mensaje como algo a ser decodificado por un público que -se infiere- estaría entrenado en una suerte de decodificación "entre líneas", lo cual remite a las formas comprendidas o habituales del pasado para interpretar mensajes en tiempos de censura. Por su parte, la respuesta de Podargo no solo acepta una suerte de modelo tradicional de comunicación (emisión, mensaje y recepción), sino que va más allá y complejiza la naturaleza de la recepción en el entendido de que integra nociones más actualizadas no solo de la existencia de distintos públicos, sino también de la presencia de grupos primarios y de líderes de opinión en la figura de la "gente que lo capta porque otra se lo dice". ${ }^{11}$ La noción actualizada de la recepción se ve expresada en la identificación de públicos activos que presentan "miles de formas de entender a los grupos", identificación que remite, a su vez, a distintas formas y funciones de la escucha. Por último, la noción de "auditorio" vincula de manera muy efectiva la dimensión espacial y acústica de un recinto con la caracterización de públicos específicos.

\section{Conclusiones}

Las estrategias de los jóvenes para lograr "sonar bien" en los espectáculos en vivo emplearon modalidades que se adaptaron plásticamente a las adversidades. La grabación de discos, en el caso de Los Tontos, ya tenía en cuenta la presentación en

\footnotetext{
31 En el contexto del estudio de la comunicación de masas y el estudio de las audiencias estadounidenses, los "grupos primarios" son aquellos que logran modificar las opiniones de individuos que lo integran. En este ámbito, los "líderes de opinión" son individuos con mayor interés en determinados aspectos de la sociedad (culturales o musicales, en este caso) que influyen en las opiniones del resto de los integrantes de estos grupos primarios (Saperas, 1985, pp. 133-35).
} 
Leandro Delgado, Federico Farachio

Eléctrico, auténtico y precario: el sonido y los nuevos públicos en los espectáculos de rock de los ochenta montevideanos

vivo a través del uso de los instrumentos básicos indispensables para encarar una performance que se preveía problemática. Esto permite apreciar la relevancia ofrecida a la presentación en vivo, que ya estaba inscrita en la grabación y que revela, de parte de los músicos, una conciencia clara de la performance como una vía principal de comunicación. Esta claridad sobre aspectos comunicacionales respecto a las características y expectativas de un público específico de parte de los músicos -podría pensarse- establece vínculos estrechos de identificación entre artistas y audiencia. De ahí quizá el lamento de Forlán Lamarque frente a identificaciones de esta naturaleza, en las que ciertos públicos se interesaban por una banda en particular, pero desestimaban al resto en el contexto de un recital multitudinario.

Se pueden señalar dos actitudes distintas frente a los espectáculos en vivo de parte de músicos y periodistas. Por un lado, los músicos, tanto los vinculados al rock como los más alejados del género, parecen tener un conocimiento más específico no solo de aspectos musicales o de sonido, sino también de los comunicacionales respecto a los públicos. Por otro, si bien los periodistas son quienes más señalan los problemas de sonido, es llamativa la ausencia de términos de uso común referidos a la tecnología de sonido ("acople", "retorno", "eco", "reverberancia" e incluso "acústica"). Esto no solo marcaría una diferencia en cuanto a los lugares ocupados en la experiencia musical. Además, destaca -a diferencia de los músicos- el énfasis cultural que hacen los periodistas sobre el lugar del rock en una tradición musical, es decir, más preocupados por la forma en la que los problemas de sonido dificultaban a los músicos, en última instancia, en hacerse escuchar en los términos exigidos por el género (la performance efectiva de lo auténtico en función de la calidad de sonido), de manera de ser ubicados con claridad tanto en una tradición como en la escena cultural del momento.

Asimismo, de Los Tontos en particular se puede considerar que parte de su éxito provino no solo de haber comprendido las características de los nuevos públicos o de haber tenido conciencia de la precariedad de la amplificación en vivo, que determinaba, eventualmente, la selección de instrumentos a ser empleados en la grabación en estudio. Su éxito también provino del despliegue de un sentido del humor e ironía que, frente a la seriedad y gravedad de las bandas centrales del punk rock uruguayo, le permitió convertirse en su momento en la primera en alcanzar un éxito masivo. Este mismo sentido del humor e irreverencia presentes en sus performances se puede observar también en El Cuarteto de Nos o La Tabaré Riverock Banda, grupos que emplearon elementos del teatro y de las artes plásticas, eventualmente trascendiendo las limitaciones de amplificación y acústica de forma de alcanzar una performance auténtica. Incluso, ambas bandas son las únicas que han sobrevivido hasta hoy logrando un arraigo popular, en el primer caso, y un alcance masivo continental, en el segundo. 


\section{Austral@municación \\ Volumen 10, número 2 (Diciembre de 2021): 461-483 ISSN (I) 2313-9129. ISSN (E) 2313-9137}

Por último, el debate alrededor de los problemas de sonido se puede considerar una expresión de los conflictos que existieron en el ámbito de la nueva democracia frente a los grupos juveniles en formación. La posibilidad del sonido de generar comunidad, tal como explica Attali (1995), permite pensar que el sonido, con problemas o sin él, estaba conformando nuevos grupos que debían ser identificados no solo como públicos consumidores. También permitió visualizar los cambios en los flujos de poder que, en el período de la dictadura y en los recitales multitudinarios de canto popular, resultaban más fáciles de ser detectados y caracterizados. La irrupción de los jóvenes músicos, del público vinculado con la cultura rock, de los críticos musicales y de los mismos empresarios complejiza no solo las relaciones de poder, sino también las agencias particulares de cada uno de estos actores en un período de renacimiento cultural.

\section{Referencias}

Anchustegui, M. (25 de noviembre de 1986). Fito Páez fue lo mejor del "Montevideo Rock". Aquí.

Anguita, E. y Cecchini, D. (16 de enero de 2020). Efecto Malvinas: cuando la dictadura prohibió la música en inglés y promovió el rock nacional que antes había censurado. Infobae. https://www.infobae.com/sociedad/2020/01/16/efecto-malvinas-cuandola-dictadura-prohibio-la-musica-en-ingles-y-promovio-el-rock-nacional-queantes-habia-censurado/.

Attali, J. (1995). Ruido: Ensayo sobre la economía política de la música. Siglo XXI.

Bayce, R. (1989). Cultura política uruguaya. Desde Batlle hasta 1988. Fundación de Cultura Universitaria.

Baltar, G. (1 de noviembre de 1986). Festival en el Teatro de Verano: la hora de los palos. La Semana.

Baltar, G. (1987). El lugar del rock, Entrevista a Los Tontos (I). La Semana.

Bonaldi, J. (1 de febrero de 1986). To Rock or not to rock. La Hora.

Blister Doc. (2014). Cooperativa del Molino [Video]. YouTube. https://www.youtube. $\mathrm{com} /$ watch? $\mathrm{v}=\mathrm{ruPqk} 3 \mathrm{O} 0 \mathrm{Pto}$.

Brando, O. (2012). La de ayer y la de hoy: cincuenta años de cultura uruguaya. En Nahum, B. (Org.), 50 años. Economía, Política, Sociedad, Cultura, Educación (pp. 501-600). Banda Oriental.

Caetano, G. y Rilla, J. (1987). Breve historia de la dictadura (1973-1985). Banda Oriental. Carbone, A. y Forlán Lamarque, R. (1987). Fuera de control. Forum Gráfica Editora.

Casanova, G. (1988). Mamá era punk. CEMA.

Da Silveira, C. (23 de marzo de 1984). En la tele. Jaque.

De Certeau, M. (1998). The practice of Everyday Life. En Storey, J.(Ed.), Cultural Theory and Popular Culture. A Reader (pp. 483-494). Prentice Hall. 
Leandro Delgado, Federico Farachio

Eléctrico, auténtico y precario: el sonido y los nuevos públicos en los espectáculos de rock de los ochenta montevideanos

Delgado, L. (2014). Cultura y comunicación de los ochenta: la década de los senderos que se bifurcan. En Delgado L. (Ed.) Cuadernos de Historia 13 (pp. 7-18). Biblioteca Nacional.

Delgado, L. (2016). La subcultura del punk rock montevideano en la crítica musical y cultural de los ochenta (1983-1987). Encuentros Uruguayos, IX(1), 111-130. https:// ojs.fhce.edu.uy/index.php/encuru/article/view/1274.

Farachio, F. (2015). Polémica sobre el rock nacional en cinco semanarios uruguayos (19851987) (Trabajo final de grado). Universidad Católica del Uruguay, Montevideo.

Forlán Lamarque, R. (24 de junio de 1987). Rock uruguayo en 1987. Jaque.

Forlán Lamarque, R. (2 de septiembre 1987). Rock en el Palacio: Un sonido Lamentable. Jaque.

Forlán Lamarque, R. (9 de septiembre de 1987). La música nos pertenece. Jaque.

Gracyk, T. (1996). Rhythm and Noise. The Aesthetics of Rock. Duke UP.

Hall, S. (1980). Codificar y Decodificar. En Culture, Media and Language (Trad. S. Delfino, pp. 129-139). Hutchinson.

Iglesias, D. (28 de noviembre de 1986a). Tres días que (casi) conmovieron a la ciudad. Brecha.

Iglesias, D. (28 de noviembre de 1986b). ¡Coca Cola es así! Brecha.

Jorge Lazaroff: mucho más de medio kilo de charla. (20 de diciembre de 1986). La Hora.

José "DeQo" Núñez. (1950-2015): Meridiano del rock en la radio uruguaya. (2 de febrero de 2015). La Galena del Sur. https://lagalenadelsur.wordpress.com/2015/02/02/ jose-deqo-nunez-1950-2015-meridiano-del-rock-en-la-radio-uruguaya/.

Marcus, G. (1993). Rastros de carmín: una historia secreta del siglo XX. Anagrama.

Moore, A. (2002). Authenticity as Authentication. Popular Music, 21(2), 209-223.

Muñoz, B.y Del Signore, G. (1991). 20 años no es nada. (La movida de los'80). En Araújo, A. M. (Comp.), Jóvenes: una sensibilidad buscada (pp. 15-32). Nordan-Comunidad.

Pattie, D. (2007). Rock music in performance. Palgrave-Macmillan.

Peláez, F. (2002). De las cuevas al Solís, 1960-1975: cronología del rock uruguayo. Perro Andaluz.

Pérez da Cunha, A. (12 de septiembre de 1985). "Los Estómagos” se comen todo. La Hora.

Phillipov, M. (2006). Haunted by the Spirit of '77: Punk Studies and the Persistence of Politics. Continuum. Journal of Communication \& Cultural Studies, 20 (3), 383-393.

Rodríguez, M. (2012). En la noche: el rock uruguayo postdictadura. Fin de Siglo.

Rodríguez Barilari, E. y Da Rosa, J. (1980). Aquí se canta, Canto Popular 1977-1980. Arca.

Saperas, E. (1985). La sociología de la comunicación de masas en Estados Unidos. Ariel. Sotelo, G. (15 de octubre de 1985). ¿En qué anda la música por aquí? Aquí. 
Austral Comunicación

Volumen 10, número 2 (Diciembre de 2021): 461-483 ISSN (I) 2313-9129. ISSN (E) 2313-9137

Sotelo, G. (11 de marzo de 1986). Los Estómagos hablan con Aquí. Aquí.

Sotelo, G. (2 de septiembre de 1986). Lo nuestro es rock de alternativa humorística (Los Tontos). Aquí.

Veloso, C. (1997). Verdade Tropical. Companhia das Letras. 